\title{
Desenhos do desenhar: pesquisa e práticas de Stephen Farthing ${ }^{1}$
}

\author{
Drawing drawn: research and practices \\ of Stephen Farthing
}

\section{Anelise Zimmermann ${ }^{2}$ \\ Stephen Farthing ${ }^{3}$}

\footnotetext{
1 Parte desse estudo faz parte da tese $\mathrm{O}$ ensino do desenho na formação em Design Gráfico: uma abordagem projetual e interdisciplinar (ZIMMERMANN, 2016), bem como parte das entrevistas compõem o filme A pesquisa em desenho, um dos episódios da série $\mathrm{O}$ desenho conectando conhecimentos, produzidos por Zimmermann (2018).

${ }^{2}$ Anelise Zimmermann- Doutora em Design (UFPE), com doutorado sanduíche (CNPq) na University of the Arts London, Reino Unido e Mestre em Artes Visuais pela UDESC. É professora efetiva do Departamento de Design da UDESC e integrante dos Grupo de Pesquisa RIDE - Rede Internacional Design/Educação (UFPE) e Literalise (UFSC) com pesquisas voltadas ao ensino do desenho, design de informação e narrativas visuais na literatura infantil. Produziu a série de filmes $O$ desenho conectando conhecimentos a partir de entrevistas com pesquisadores, educadores, artistas e designers no Reino Unido. A série recebeu o Prêmio Destaque na Bienal Brasileira de Design Gráfico de 2019 na categoria Pensando o Design. Lattes: http://lattes.cnpq.br/8548816949021546 E-mail: anelise.zimmermann@gmail.com

${ }^{3}$ Stephen Farthing- No ensino do desenho e pintura atuou como Head of Painting e Head of Department of Fine Art no West Surrey College of Art and Design, Ruskin Master na Ruskin School of Fine Art e Professorial Fellow em St Edmund Hall, da Oxford University. Entre 2000 e 2016 atuou como pesquisador na University of Arts London onde assumiu o posto de Rootstein Hopkins Research Chair of Drawing. Nessa instituição, integrou o Centre for Drawing, grupo de estudos e práticas em desenho, participando da elaboração do currículo Drawing Qualification, implementado em escolas do Reino Unido. É artista, membro eleito da Royal Academy of Arts de Londres, com publicações e produções audiovisuais que exploram os territórios da pintura e desenho. Website:http://stephenfarthing.co.uk
} 


\title{
Resumo
}

Este artigo tem como objetivo apresentar um panorama dos estudos em desenho realizados por Stephen Farthing, artista e pesquisador. Esses estudos incluem definições e taxonomias para o desenho, elaborados com o propósito de ampliar a compreensão de sua prática e ensino, estendendo-se para além do território das artes. Farthing utiliza o próprio desenho como meio de investigação. O levantamento desses estudos foi realizado por Zimmermann (2016) durante o doutorado sanduíche na University of the Arts London, período no qual teve a supervisão de Farthing, com acesso a seu acervo de desenhos e publicações e a realização de entrevistas gravadas ${ }^{1}$. Por fim, esses estudos tanto representam o percurso de pesquisa de Farthing, como também demostram a interdisciplinaridade do desenho como um conhecimento que transita entre áreas, um meio de investigação e uma função intelectual com territórios ainda a serem explorados.

\section{Palavras-chave}

Desenho; taxonomia; interdisciplinaridade.

\begin{abstract}
This article presents an overview of the studies into drawing by Stephen Farthing, artist, and researcher. His studies include definitions and taxonomies of drawing developed to broaden the understanding of the drawing practice and teaching beyond the territory of the arts field. In these studies, Farthing uses drawing itself as a means of investigation. The data was collected by Zimmermann (2016) during her doctorate studies at the University of the Arts London, with the supervision of Farthing and access to his collection of drawings, publications, and interviews. Finally, the studies track the journey into drawing research by Farthing, as well as it shows the role of drawing as an interdisciplinary knowledge, a means of investigation, and an intellectual field with territories to be explored.
\end{abstract}

\section{Keywords}

Experimentalism; Structures.; Sculpture; Architecture; Drawing and Design.

Project 1. Center for Architecture and Arts, USU, Rio de Janeiro, 1993.

\section{ISSN: 2447-1267}

\footnotetext{
1 Parte dessas entrevistas compõem o filme A pesquisa em desenho, um dos episódios da série O desenho conectando conhecimentos, produzidos por Zimmermann (2018).
} 


\section{Introdução}

Especialmente a partir dos anos 2000, a pesquisa em desenho no Reino Unido ganhou espaço nas academias a partir de uma abordagem renovada, com a reformulação de conceitos, taxonomias e fundamentação teórica, com um vasto campo para a pesquisa, ampliando também a sua compreensão como prática como um meio autônomo e meio para outros meios. Um dos responsáveis por essa reformulação da compreensão do desenho foi Stephen Farthing, artistas, eleito membro da Royal Academy of Arts de Londres. Dentro do ensino do desenho e pintura atuou como Head of Painting (1985-87) e Head of Department of Fine Art (1987-89) no West Surrey College of Art and Design, foi nomeado Ruskin Master na Ruskin School of Fine Art e Professorial Fellow em St Edmund Hall, Oxford. Em 2000 foi escolhido para o posto de Rootstein Hopkins Research Chair of Drawing na University of Arts London, onde atuou como pesquisador e professor até 2016. Nessa instituição, foi um dos líderes do Centre for Drawing, coordenando pesquisas, eventos, publicações, exposições em desenho e a elaboração do currículo Drawing Qualification, formação implementada em escolas do Reino Unido. O seu interesse pela pesquisa em desenho surgiu a partir de seus experiências de docência, utilizando-se do próprio meio, junto à escrita, como recurso para refletir e exemplificar suas elaborações conceituais. Assim, esse artigo apresenta um panorama dos estudos em desenho pelo desenho desenvolvidos por Farthing, bem como sinalizam proposições futuras para a área.

\section{Estudos do desenho pelo desenho}

Em seu percurso de pesquisa, Farthing utilizou variadas formas de representação visual para explorar os territórios do desenho, estabelecer conexões entre disciplinas e pensar a prática do desenhar como um sistema. Seus estudos iniciais utilizam a linguagem cartográfica, em uma série produzida a partir de 2005, na qual investigou o desenho em relação aos seus usos e funções. No primeiro estudo dessa série (Fig.1), a arte aparece inscrita na posição central de um mapa, no alto de uma colina, interligando-se ao território do design, seguido da arquitetura e cartografia, tendo a matemática, a escrita e as notações musicais e coreográficas em sua extremidade. Os desenhos em arte são exemplificados pelos nomes de Leonardo da Vinci e Rembrandt, enquanto que os demais territórios são associados a usos do desenho em projetos em design, tatuagens, mapas, desenhos das marcações nas estradas e até mesmo, shows pirotécnicos ${ }^{1}$, entre outros.

\footnotetext{
${ }^{1}$ Apesar de ser um evento tridimensional, os shows pirotécnicos podem ser percebidos como desenhos bidimensionais quando vistos de longe.
} 


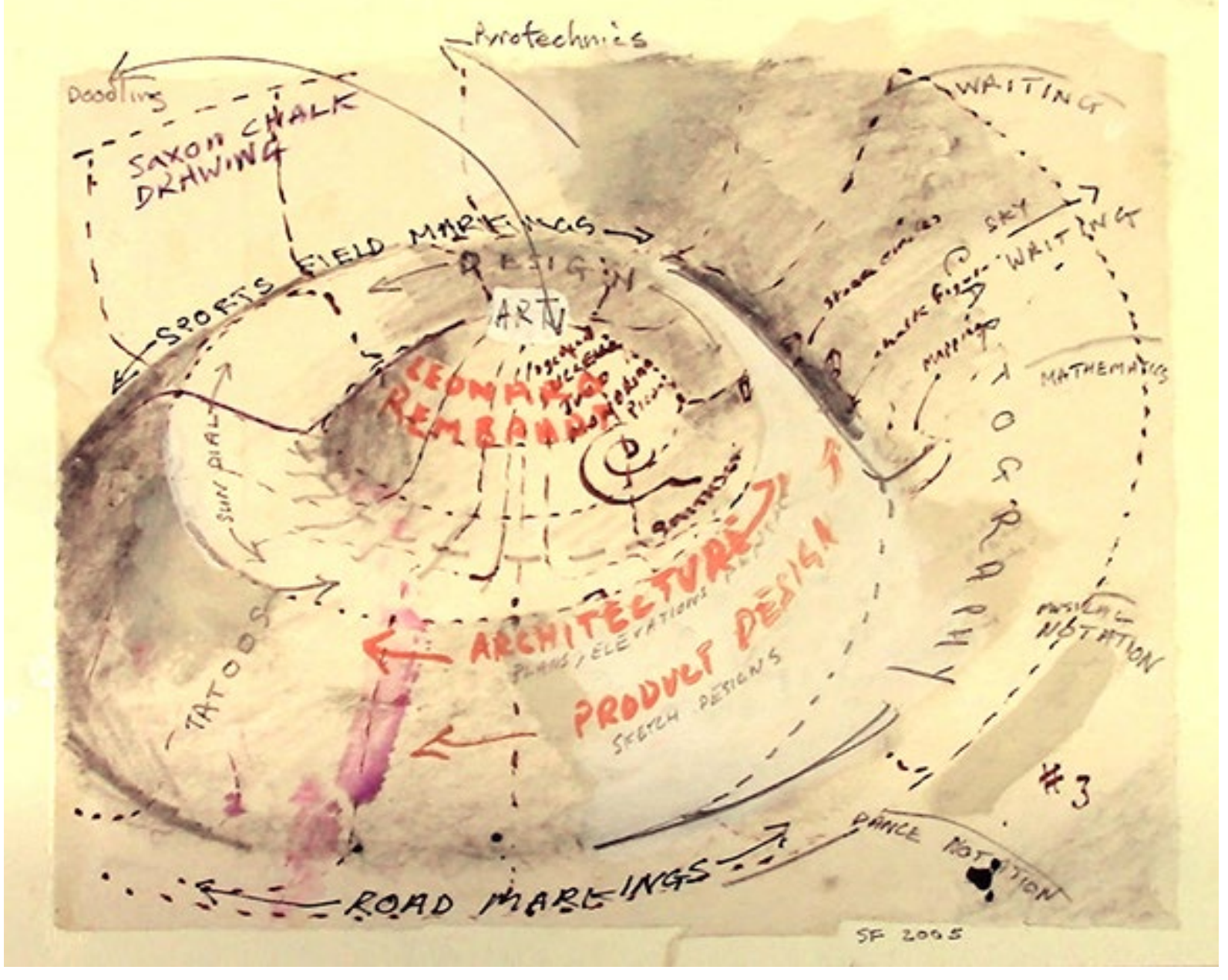

Fig. 1. Farthing, Exploratory drawings of drawing. 2005. Caneta, nanquim e gouache sobre papel japonês. Fonte: Arquivo pessoal

À medida que foi acrescentando outros usos e formas de desenho ao mapa, Farthing passou a questionar a posição central da arte, o que o levou a sua reelaboração. Ele argumenta, "[...] nossa capacidade em ver e compreender o panorama do desenho é muitas vezes obscurecida por uma preferência cultural em colocar a arte no primeiro plano" (2011, p. 21, tradução nossa). Dessa forma, a relação conceitual entre desenho e arte (e um conceito bastante específico de arte, muitas vezes relacionado a um período histórico) restringe a compreensão do que é identificado como desenho. Dentro dessa perspectiva "se nós acreditamos que uma imagem é arte, nós vamos classificá-la como um desenho. Se o teste da arte falhar, nós vamos voltar a um conjunto mais amplo de descrições - mapa, diagrama, plano ou talvez até mesmo poesia concreta" (FARTHING, 2014, p. 31, tradução nossa). Com base nesses aspectos, em seus estudos cartográficos seguintes (Fig.2), a posição mais elevada do mapa é ocupada pela tatuagem, envolvida pelo desenho de memória e o desenho de observação. $O$ interesse em entender o desenho passou a residir nas capacidades envolvidas em suas elaborações e interpretações. 


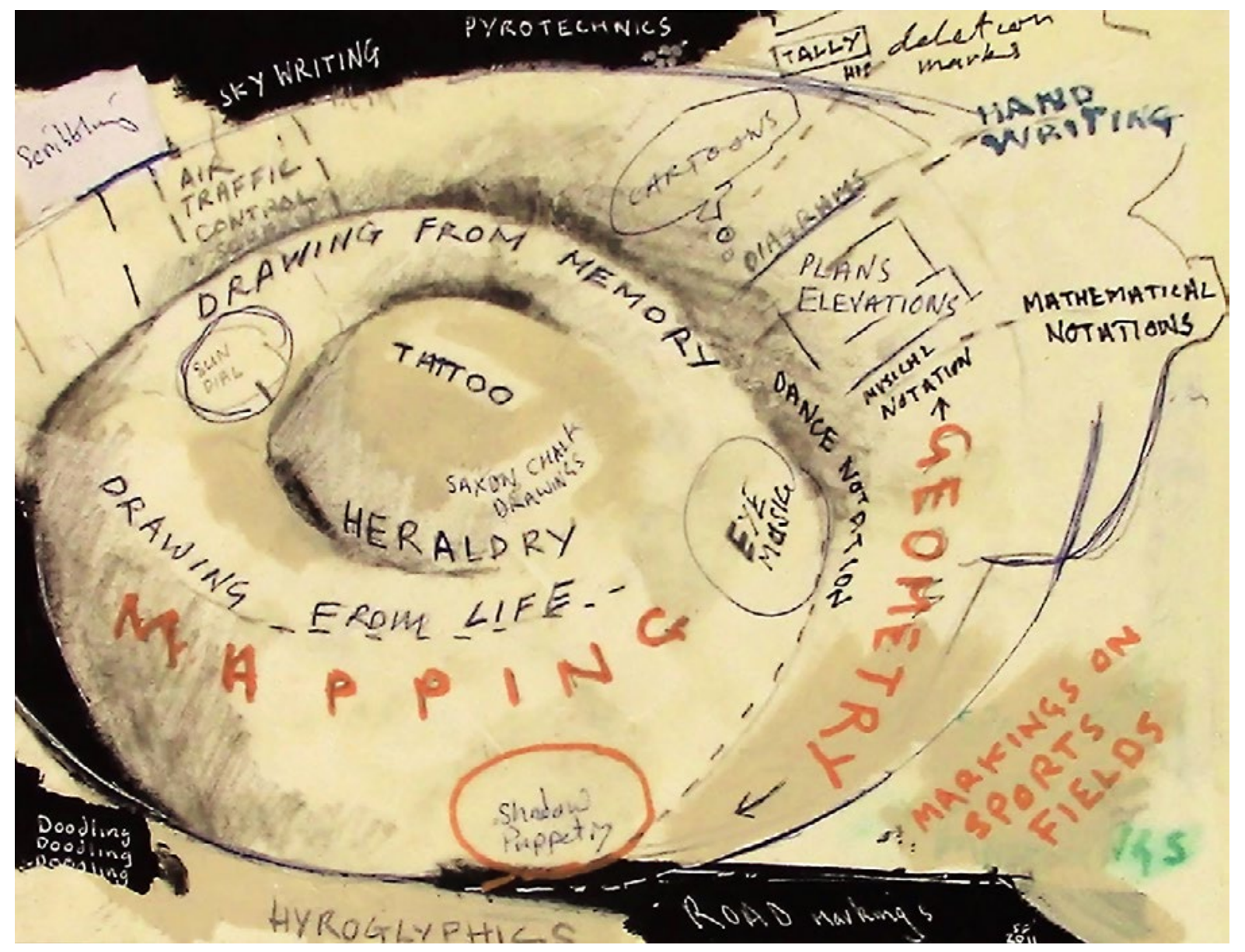

Fig. 2. Farthing, Exploratory drawings of drawing. 2011. Caneta, nanquim e gouache sobre papel japonês. Fonte: Arquivo pessoal.

Nesse estudo, entretanto, as relações entre os variados tipos de desenho não se tornam visíveis, o que fez com que Farthing, em seguida, passasse a abordar o desenho por uma perspectiva interdisciplinar, utilizando a forma diagramática de representação. Para isso, foi tomado como referência o diagrama das linhas do metrô de Londres, de Harry Becks (1931). Assim, em O Plan de Dessin (Fig.3), Farthing estabelece o mapeamento das aplicações do desenho, relacionadas às suas funções, identificadas como 'As linhas': Decorativa, Sistemas de controle, Desenvolvimento das ideias, Comunicação de instruções, Registro de informações e Entretenimento.

Os cruzamentos e interconexões entre as linhas são representados como as 'estações do metrô', ou seja, as convergências entre os diferentes campos do desenho. Por exemplo, os desenhos infantis tanto se encontram na 'Linha Amarela', responsável pelo desenvolvimento de ideias, quanto na 'Linha Violeta', relacionada ao entretenimento. Já, o próprio desenho de diagrama aparece na conexão entre a 'Linha Azul', referente à comunicação de instruções, a 'Linha Amarela', correspondente ao desenvolvimento de ideias, a 'Linha Verde', responsável pelo registro de informações e, finalmente, a 'Linha Vermelha', relacionada aos sistemas de controle. 


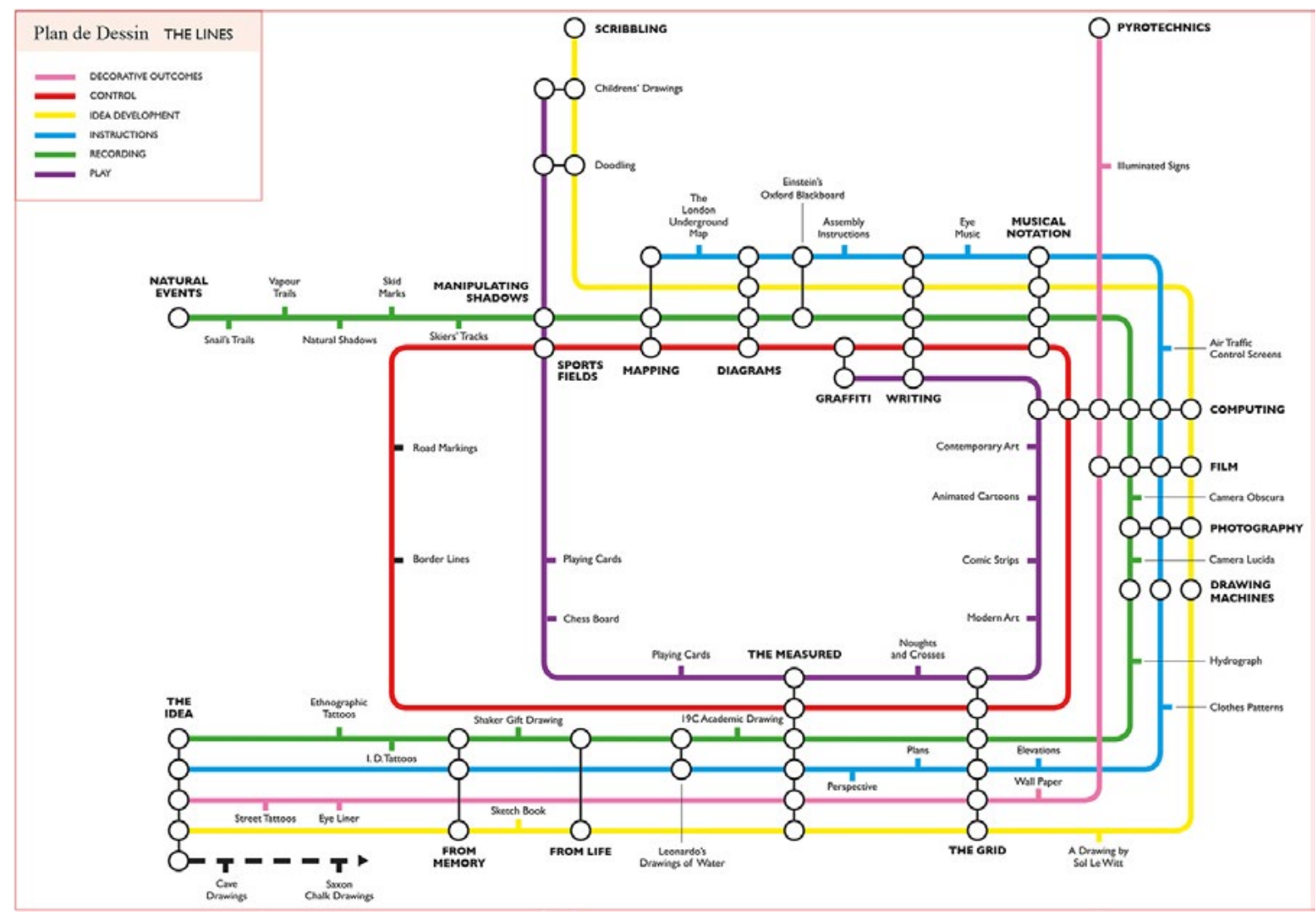

Fig. 3. Farthing, Plan de Dessin, 2006. Desenho digital. Fonte: Arquivo pessoal

Posteriormente, o interesse nos estudos de Farthing partem de uma abordagem relacionada primordialmente ao desenvolvimento da comunicação humana. Nesse sentido, toma-se como premissa o entendimento de que o desenho, assim como a linguagem verbal, surge pela necessidade de medir, calcular, imaginar, registrar e inventar. Farthing considera que:

\begin{abstract}
Além de nossa habilidade em fazer marcas sobre o pó, estimar e medir com precisão, as duas descobertas mais importantes dentro do desenho foram: a constatação de que elementos tridimensionais podem ser representados em duas dimensões por um contorno, e então a constatação de que lugares, coisas, tempo, direções e quantidades podem ser representados por marcas que têm apenas uma breve relação com o que elas representam. (FARTHING, 2011 , p. 22, tradução nossa).
\end{abstract}

É por esses aspectos que Farthing então estabelece uma definição para o desenho que diz ser a tradução de eventos multidimensionais em informações bidimensionais compreensíveis, assim como as palavras, os números e as notações (musicais, por exemplo). Por eventos multidimensionais entendem-se ocorrências que podem existir fisicamente ou não. Já o aspecto 'compreensível', está relacionado ao contexto no qual um desenho foi feito e ao contexto do seu observador, ou seja, são essas experiências que permitem que seus conteúdos sejam acessados.

Quanto aos seus formatos, essa definição contempla, sem atribuir diferentes 
valores, os desenhos de esboços, desenhos técnicos, diagramas, ilustrações, cartoons, desenhos de moda, mapas, desenhos geométricos, tatuagens, desenhos feitos na areia com um graveto, desenhos produzidos por meio de instrumentos digitais, entre tantos outros. Também essa definição, ao se aproximar da palavra, dos números e das notações, expõe seu caráter interdisciplinar, transitando entre áreas e campos do conhecimento.

Com base nesses aspectos, Farthing (2011) se dedicou então ao estudo de uma taxonomia a partir de duas vertentes: o Desenho Pictórico e o Desenho Conceitual. Essas duas categorias, e suas subcategorias, são explicadas por meio de duas representações, uma elaborada a partir da linguagem conceitual, no formato de diagrama (Fig. 4), e outra a partir de elementos pictóricos, com o desenho de mapotecas (Fig. 5).

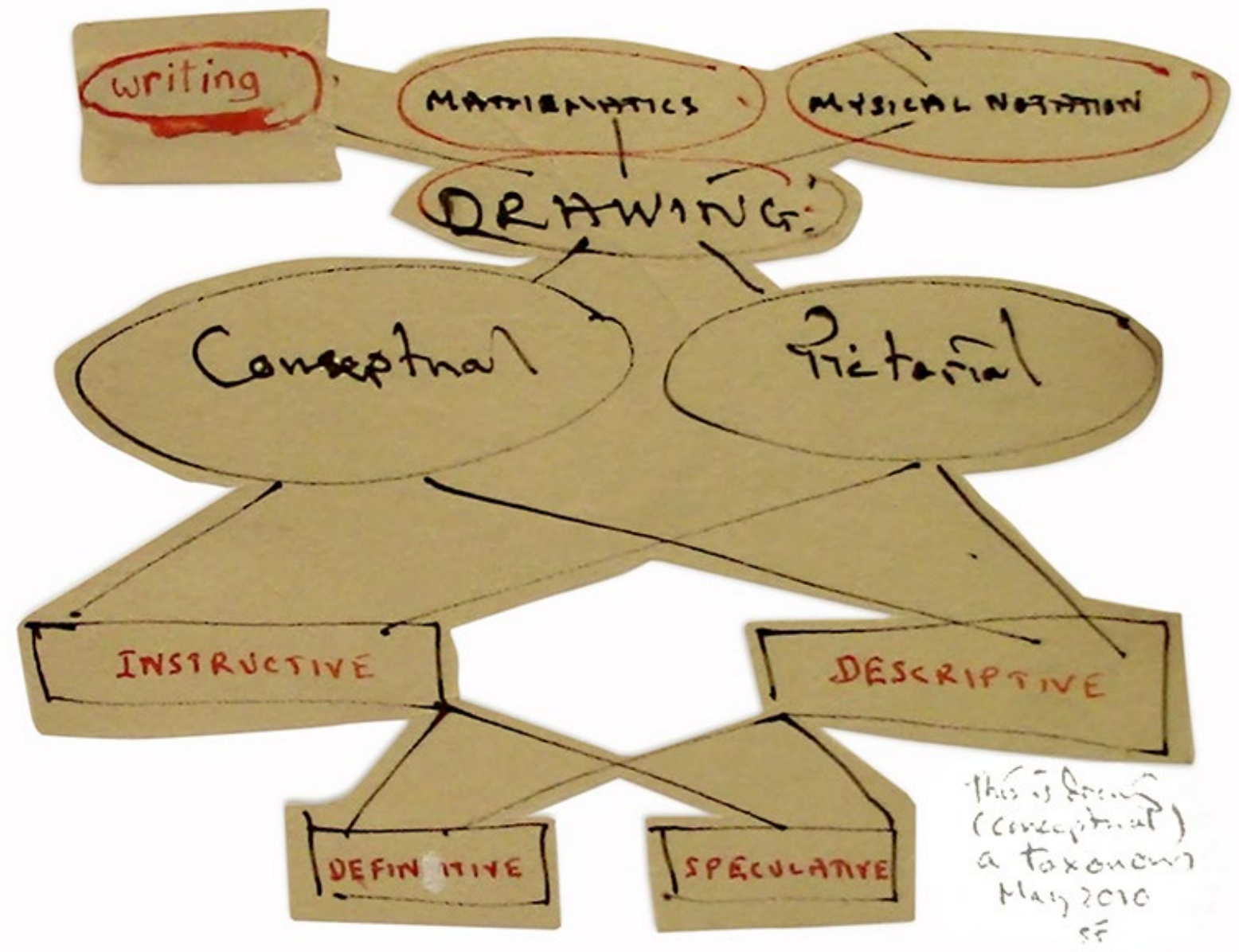

Fig. 4. Farhting, Conceptual image of 'The first taxonomy of drawing: pictorial drawing', 2010. Caneta e nanquim sobre papel. Fonte: Arquivo pessoal.

A diferença entre as duas principais categorias reside substancialmente, na forma como os desenhos são lidos e suas informações são acessadas. $\bigcirc$ desenho Conceitual parte de abstrações e requer a habilidade em ler e estabelecer sentido a partir dessas abstrações. Assim, os desenhos conceituais "[...] não são construídos a partir de uma narrativa. A narrativa é localizada ou na margem ou em algum lugar além" (FARTHING, 2011, 23, tradução nossa). Ou seja, esses desenhos remetem 
a elaborações visuais que não necessariamente guardam relação direta com suas representações, tendo como exemplo, os diagramas e os esboços nas fases inicias de um projeto. Já o desenho Pictórico envolve a habilidade de reconhecer elementos a partir da relação entre suas formas e contornos com as aparências externas de eventos multidimensionais, permitindo falar por si mesmo. As subcategorias, representadas pelas gavetas Definitivo ou Especulativo da mapoteca, se referem aos propósitos do desenho como fins ou como meios. Já, de acordo com suas formas, os desenhos também podem ser classificados como Descritivo ou Instrutivo. Assim, com base nesse modelo, pode-se entender que, em um mesmo projeto, desenhos podem partir do caráter Conceitual ou Especulativo (fase de estudos e experimentação) e no decorrer do projeto podem assumirem o caráter Pictórico Definitivo Instrutivo ou Descritivo (como em desenhos técnicos de produção).

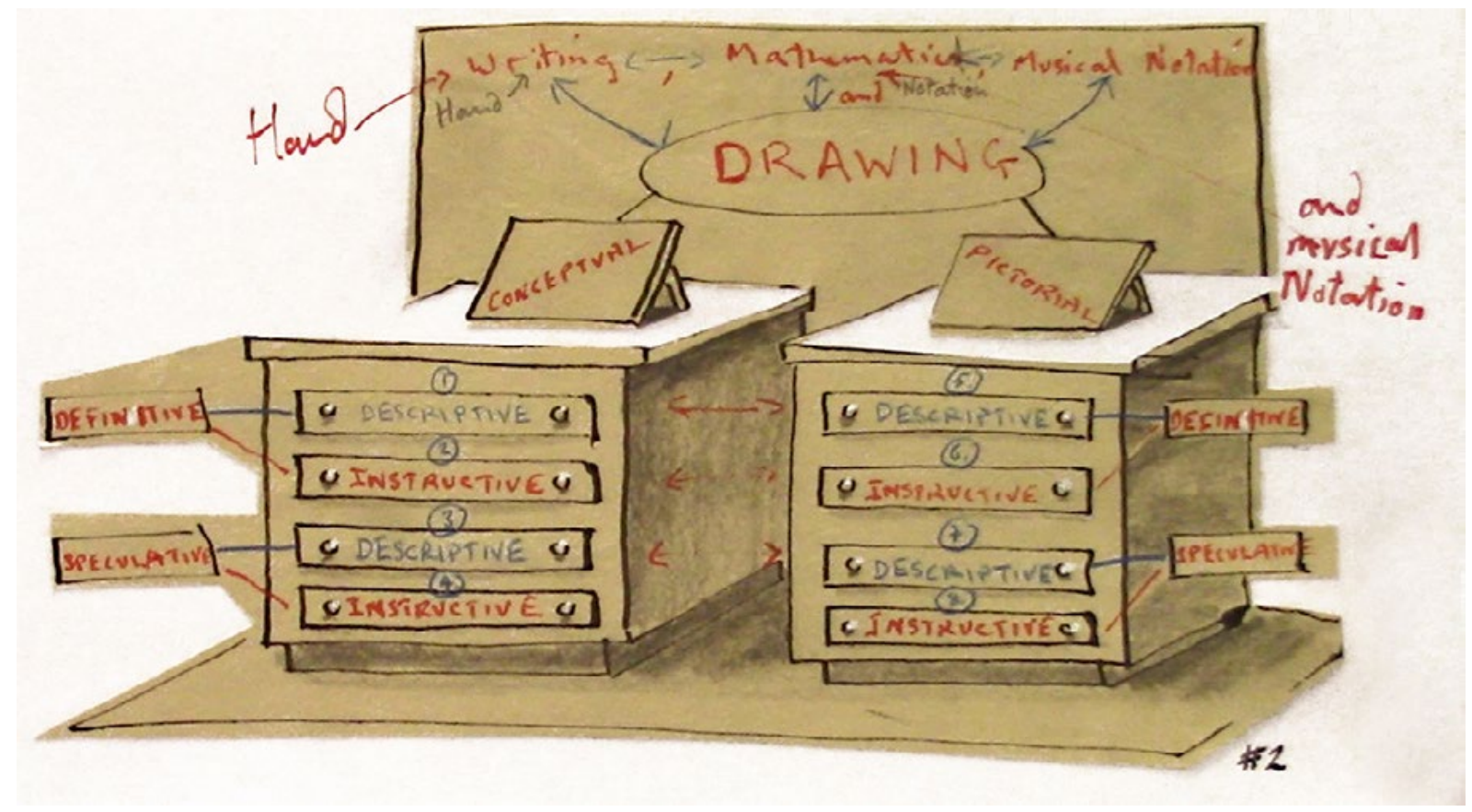

Fig. 5. Farhting, Pictorial image of 'The first taxonomy of drawing: pictorial drawing', 2010. Caneta e nanquim sobre papel. Fonte: Arquivo pessoal.

Ao defender esse modelo taxonômico, Farthing (2011) explica que o mesmo abarca os mais variados tipos de desenhos de maneira atemporal, independentemente dos instrumentos utilizados, suporte ou autoria e coloca sua função e formas de acesso como elementos primordiais ao desenho.

Nesse sentindo, Farthing chama a atenção para a relevância dessa compreensão ampliada do desenho no ensino. Ele diz:

Museus geralmente organizam desenhos por data, nome dos autores, país de origem. Mas se você está ensinando alguém a desenhar seria mais razoável não se ater aos nomes dos autores famosos, a data em que foram feitos. Isso é algo interessante, mas não é crucial para entender um desenho, mas sim observá-lo a partir de seu propósito, o porquê desse desenho ter sido feito. (ZIMMERMANN, 2015, tradução nossa) 
A partir dessa taxonomia Farthing (2012) passou a questionar 'o que é um bom desenho', tema central de um evento e publicação das quais participou, promovidos pela University of the Arts London, reunindo diversos outros pesquisadores da área². Segundo Farthing (2012), é na relação entre o desenho e a sua proposição que se encontram os argumentos que sustentam as suas qualidades. Assim, bons desenhos são aqueles que

[...] nos ajudam a lidar com as estradas, as águas costeiras e os terminais do aeroporto; os desenhos que orientam a nossa energia quando jogamos tênis, dirigimos carros ou atiramos em alvos; e, finalmente, [...] que fazem nossos pensamentos visíveis daquilo que projetamos, explicamos e sonhamos. (FARTHING, 2012, p. 31).

Pensando pela perspectiva do ensino, essa compreensão das qualidades de um desenho oferece critérios de avaliação que vão além de análises por seus aspectos técnicos ou artísticos, incluindo o desenhador e o observador em uma relação de diálogo.

Posteriormente, Farthing (2014) apresenta a sua segunda taxonomia, baseada em um conjunto de válvulas e planos interligados em um sistema orgânico (Fig.6). O desenho, a notação e a escrita, encontra-se na base da estrutura, interligados às válvulas do desenho Conceitual e Pictórico. Seguindo o percurso, encontram-se os planos Sistemático ou Improvisado, Mesurável ou Estimativo, Mecânico ou Manual. Esse sistema alimenta os seis 'genus' do desenho, identificados como: Mapeamento, Pontuação, Traçado, Diagramático, Esboço e Técnico. Os exemplos de 'genus' vão desde telas de controle de tráfego aéreo, até notações musicais.

Assim como o estudo anterior, esse modelo tem como objetivo contemplar as mais variadas formas de desenho, identificado algumas de suas especificidades em relação às suas funções e formas de elaboração. A compreensão dessa taxonomia também explora a relação entre desenho e escrita.

Na série de desenhos seguinte, as representações taxonômicas tomam como referência pictórica e conceitual os estudos anatômicos de Leonardo da Vinci, em específico, os desenhos de olhos e cérebro. A visão, representada pelos olhos, alimenta os sistemas da escrita, do desenho e das notações. Esses três sistemas se conectam com os órgãos seguintes, classificados como Pictórico e Conceitual, e sequentemente, os órgãos do Improviso e do desenho Sistêmico. Em seguida, pode-se tomar outros dois caminhos, do Mesurável ou do Estimável, chegando finalmente ao 'genus' do Esboço ou do Mapeamento. Esses dois percursos são exemplificados nas Figuras 7 (esquerda) e 8 (direita), mostrando respectivamente o caminho da poesia concreta e do desenho de mapas.

2 O evento Drawing Out 2012 (UAL) teve como propósito responder à pergunta O que é um bom desenho? O compilado das discussões, somados a artigos escritos por participantes, geraram a publicação The Good Draw (FARTHING; CHORPENING; WIGGINS, 2012). 


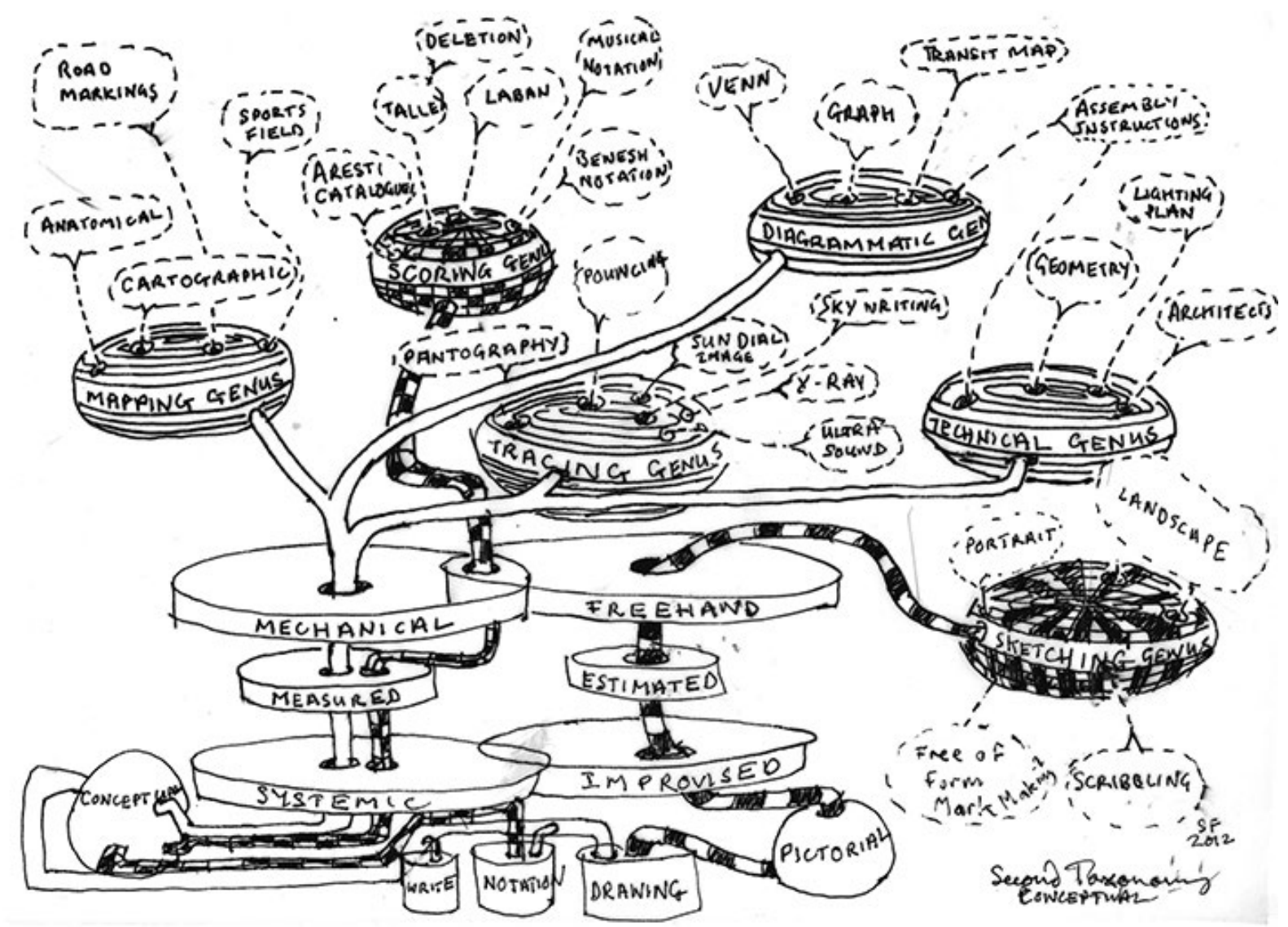

Fig. 6. Farthing, Diagrammatic sketch for the second 'Taxonomy of Drawing', 2012. Caneta e nanquim sobre papel. Fonte: Arquivo pessoal

Em seu estudo seguinte, Farthing ampliou o modelo anterior, desenvolveu os sistemas de seis 'genus' do desenho: Técnico, Diagramático, de Mapeamento, Esboço, Traçado e Partitura/marcação. Nessa representação (Fig. 9), foram acrescentadas subcategorias dentro de cada 'genus'. Por exemplo, o desenho de esboço pode compreender o esboço de observação, o esboço de memória, de imaginação, e de perspectiva. Assim, foram ampliadas as possibilidades de percurso do desenhar em relação às suas funções e aplicações. 

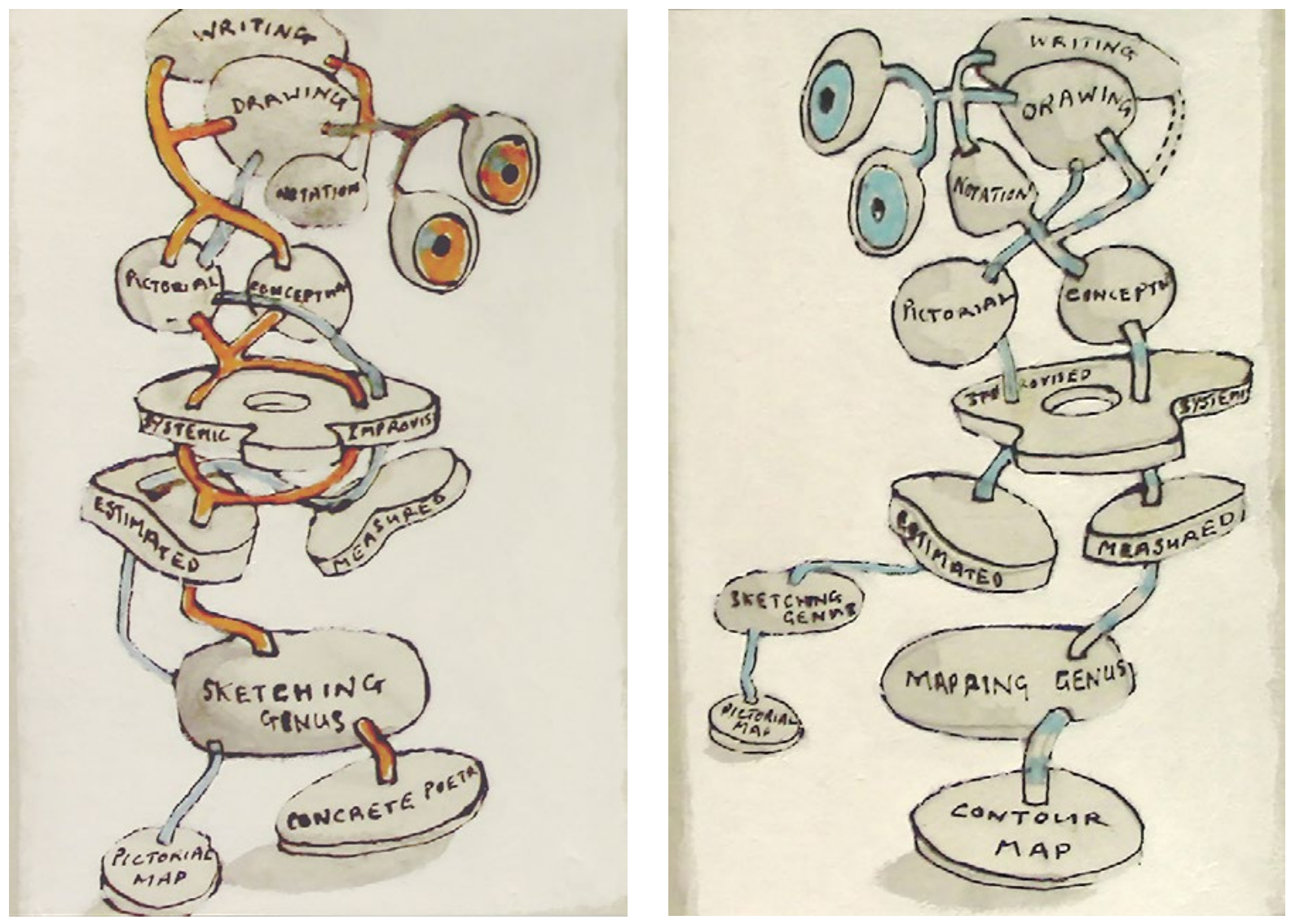

Fig. 7. Farthing, Diagrammatic drawing for Drawing and writing, the intersection: concrete poetry, 2015. Nanquim e gouache sobre papel. Fonte: Arquivo pessoal.

Fig. 8. Farthing, Diagrammatic drawing for Drawing and writing, the intersection: map, 2015.

Nanquim e gouache sobre papel. Fonte: Arquivo pessoal.

Por fim, Farthing se dedicou a uma reformulação desse último modelo e a uma redefinição do desenho, considerando uma maior aproximação com a escrita. Em seu estudo seguinte (Fig. 10), o processo do desenhar é entendido como um atividade de modelar ou definir o pensamento, traduzido em uma imagem estática bidimensional. Comparado a formulação anterior, o sentido da visão, representado pela figura dos olhos, teve sua proporção reduzida de forma significativa, enquanto que, a representação do pensamento, dada pela figura do cérebro, foi incluída com destaque. Assim, entende-se que o cérebro compreende o sistema que opera os estímulos visuais, ou seja, a visão registra as imagens, mas é o cérebro (ou as informações registradas no cérebro), que determina com o que se parecem e o que significam. 


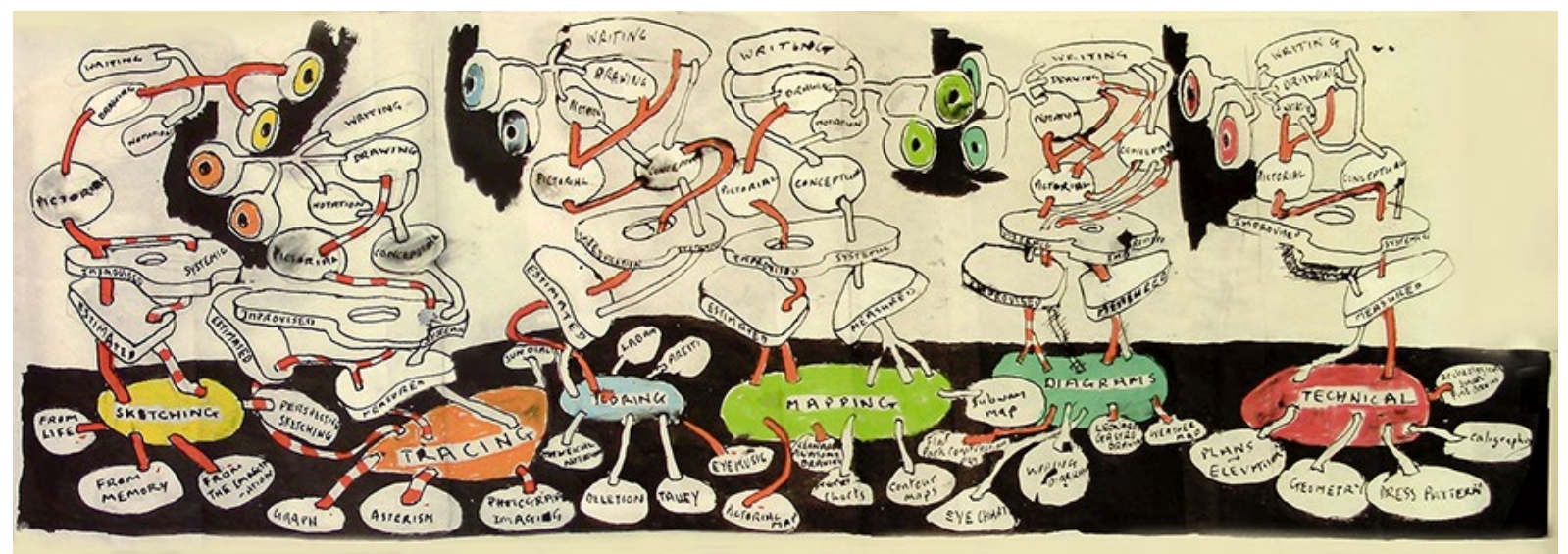

Fig. 9. Farthing, Second Taxonomy of Drawing, 2015. Nanquim e gouache sobre papel japonês. Fonte: Arquivo pessoal.

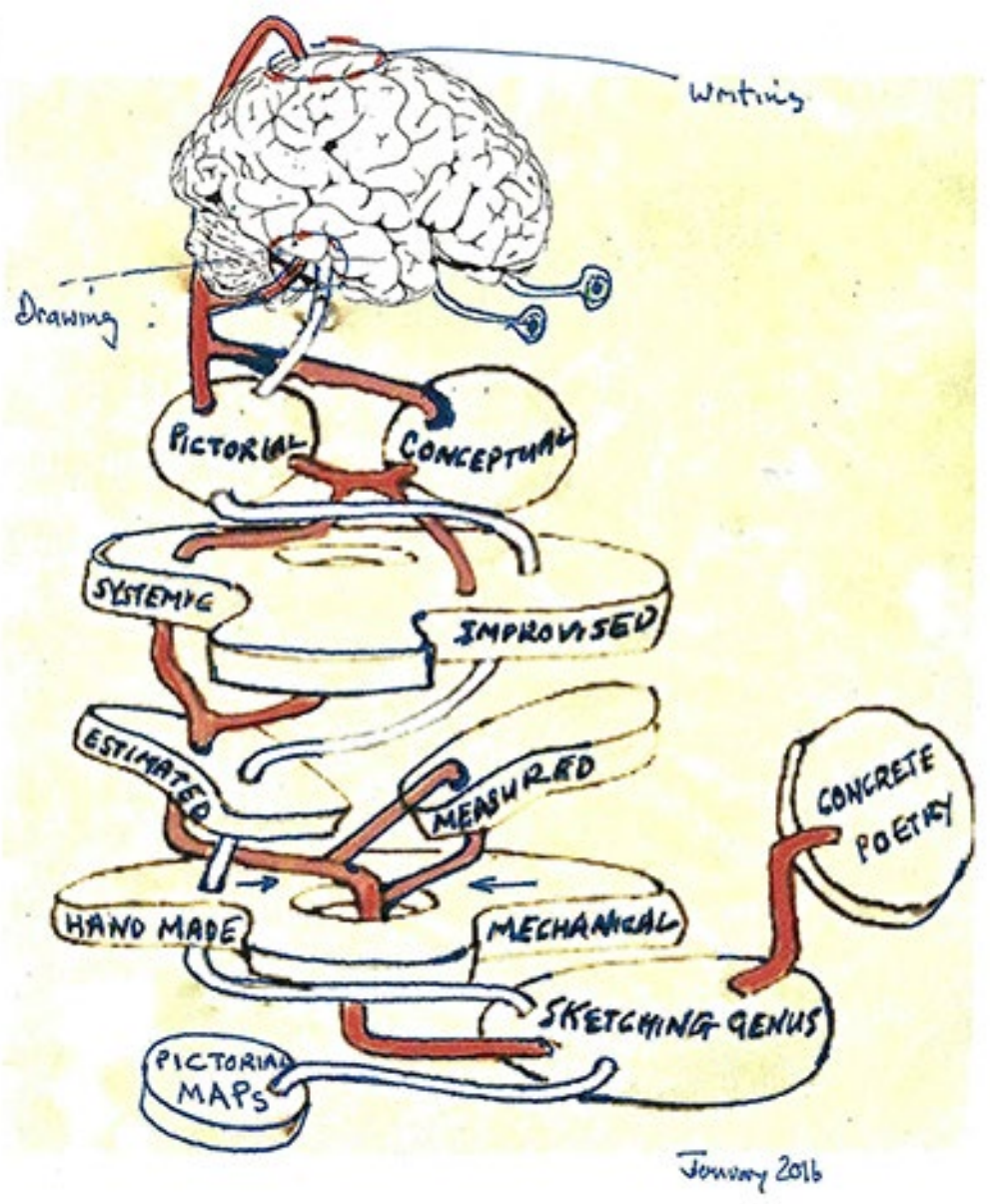

Fig. 10. Farthing, A Taxonomy of Drawing: Drawing and Writing, 2016. Nanquim e gouache sobre papel. Fonte: Arquivo pessoal.

Nessa proposta, considera-se que:

Durante o processo de criação, é possível perceber a força da relação que existe entre a escrita e o desenho, pela facilidade com que uma mão treinada se move livremente entre eles. Isso acontece, suspeito, porque ambos fazem 
parte de nossa alfabetização, como instrumentos de representação; e ambos são recursos criados para o gerenciamento da matéria multidimensional. $O$ que os separa, são os alfabetos, as gramáticas e a maneira como são lidos. (FARTHING, 2016, s.p., tradução nossa).

Assim, Farthing estabelece uma relação entre o desenho e a formulação da linguagem, a modelagem do pensamento e o movimento intelectual entre as percepções do mundo exterior, bem como com as emoções internalizadas. Nesse sentido, estudar a aprendizagem da linguagem escrita, dos gestos e do desenho no desenvolvimento infantil, de forma interligada, pode contribuir para uma compreensão mais ampliada do processo do desenhar como um recurso do pensamento. Do mesmo modo, Farthing destaca a importância da aprendizagem do desenho como uma função intelectual interdisciplinar, indo muito além de um aprendizado de técnicas ou de desenvolvimento motor.

Muitos dos problemas do mundo ainda consistem na falta de compreensão e comunicação entre as pessoas. Suspeito que a aprendizagem do desenho, como forma de pensamento visual e como diálogo interdisciplinar, poderia ampliar nosso conhecimento de mundo e auxiliar na solução de muitos desses problemas (FARTHING, 2020, entrevista).

Assim, o pesquisador chama a atenção para a relevância do ensino do desenho, não apenas como conteúdo das Artes, como geralmente aparece nos currículos escolares e acadêmicos, mas como um conhecimento próprio, assim como a língua escrita. Ele também identifica a necessidade de estudos em desenho com uma maior aproximação entre os diversos campos do conhecimento, sobretudo o campo da antropologia, da linguística e da neurologia.

Por fim, os estudos de Farthing fornecem subsídios para o debate amplo e crítico quanto às abordagens convencionais do ensino e práticas na área, além de instigarem novas possibilidades em pesquisa, corroborando uma compreensão mais ampla e profunda do desenho pelo próprio desenhar.

\section{Considerações Finais}

O percurso de estudos em desenho de Farthing mostram, sobretudo, que o próprio desenhar é um recurso importante na elaboração do pensamento e formulações de conhecimentos, auxiliando nas associações de ideias, especulações, categorizações e organizações de sistemas. Enquanto seus desenhos cartográficos identificam o desenho como território de múltiplos conhecimentos, também mostram a dificuldade de limitar esses territórios. Já, o estudo em forma de diagrama, permite identificar as mais diversas aplicações do desenho, interligadas as suas funções práticas, sem atribuições de valores, ou delimitação de um ponto central. Em segui$\mathrm{da}$, os desenhos das taxonomias por mapotecas, abrem gavetas para categorias 
mais amplas do desenho, relacionadas ao seu processo de elaboração e interpretação, incluindo a participação dos propósitos do desenhador e as experiências do observador. Por fim, os estudos por meio de formas orgânicas, ampliam a compreensão do desenho como um sistema complexo, de relação recíproca entre elaborações do mundo exterior, o indivíduo e o pensamento.

Concluindo, esses estudos apresentam o campo do desenho como um vasto território ainda a ser explorado, permitindo a aproximação de áreas do conhecimento, teoria e prática, pesquisa e ensino, ampliando assim, suas possibilidades como meio de compreensão e representação das relações do indivíduo no mundo.

\section{Referências}

FARTHING, Stephen. The Bigger Picture of Drawing. In: KANTROWITZ, A.; BREW, A.; FAVA, M. (Ed.). Thinking through drawing: practice into knowledge. Proceedings of an interdisciplinary symposium on drawing, cognition and education. New York: Columbia University, 2011, p. 21-25.

FARTHING, Stephen, CHORPENING, K.; WIGGINS, C. (Org.). The good drawing. London: CCW, 2012.

FARTHING, Stephen. Taxonomias do desenho: entrevista [ago. 2015]. Entrevistadora: Anelise Zimmermann. Londres, 2015, 1 arquivo .mp4. (60 minutos). Entrevista concedida para tese.

FARTHING, Stephen. Drawing and Writing: the Intersection. Draw Event: Interrogating interdisciplinary approaches to drawing. University of the Arts London: Londres, 2016. Disponível em: <https://draw.myblog.arts.ac.uk/2016/01/19/draw-event-drawing-andwriting-the-intersection/>. Acesso em: 28 Jul. 2020.

FARTHING, Stephen. Intersecções do desenho e a escrita: entrevista [jul. 2020]. Entrevistadora: Anelise Zimmermann. Florianópolis (realizada online), 1 arquivo .mp3. (20 minutos). Entrevista concedida para artigo.

O desenho conectando conhecimentos. Episódio 1: A pesquisa em desenho. Anelise Zimmermann. Londres/Florianópolis, Editora UDESC. 1 DVD (20 min), MP4, color. Português/ Inglês, 2018. Disponível em: <www.pesquisaemdesenho.com>. Acesso em: 30 Jul. 2020.

ZIMMERMANN, Anelise. O ensino do desenho na formação em Design Gráfico: uma abordagem projetual e interdisciplinar. Tese Doutorado - Centro de Artes e Comunica-ção/ Design, Universidade Federal de Pernambuco, Recife, 2016, p. 221.

Recebido 02 de agosto de 2020.

Aprovado 04 de agosto de 2020. 